NUREG/CR-0772

PNL-3019

\title{
Auditing Measurement Control Programs
}

Prepared by F. P. Roberts, R. J. Brouns

Pacific Northwest Laboratory

Prepared for

U. S. Nuclear Regulatory

Commission 


\section{NOTICE}

This report was prepared as an account of work sponsored by an agency of the United States Government. Neither the United States Government nor any agency thereof, or any of their employees, makes any warranty, expressed or implied, or assumes any legal liability or responsibility for any third party's use, or the results of such use, of any information, apparatus product or process disclosed in this report, or represents that its use by such third party would not infringe privately owned rights. 
F. P. Roberts

R. J. Brouns

October 1979

Prepared for

the Safeguards Standards Branch

Office of Standards Development

U.S. Nuclear Regulatory Commission under a Rëlated Services Agreement with the U.S. Department of Energy Contract EY-76-C-06-1830

FIN No. B20149

Pacific Northwest Laboratory

Richland, Washington 99352 



\section{ABSTRACT}

This report discusses the requirements and a general procedure for auditing measurement control programs used in special nuclear material accounting. The areas of measurement control that need to be examined are discussed and a

$\because \quad$ suggested checklist is included to assist in the preparation and performance of the audit. 



\section{SUMMARY}

Nuclear Regulatory Commission (NRC) licensees who are required to implement and maintain formal measurement control programs for measurements made for Special Nuclear Material (SNM) control and accounting must audit the programs annualiy. (1) The purpose of the audits is to verify that the measurement control program complies with the pertinent NRC regulations and license conditions and adequately performs its function of monitoring and controlling measurement quality. (See footnote (c), page 1.)

Audits can be performed by members of the licensee's staff if individuals are available who have the requisite education and experience. These include an understanding of measurement technology, measurement control, and the techniques of auditing. Because auditors are expected to make independent judgments concerning compliance and adequacy they should not have responsibilities for the management or operation of the measurement control program.

The audit consists of a comprehensive examination of all aspects of measurement control. The principal areas to be investigated are:

- program management and organization

- management policies and procedures

- measurement control procedures

- measurement control data collection and analysis

- records and reports

- previous audits.

The findings of the audit are summarized in a report to management that lists each item of noncompliance, conditional acceptability, and poor practice. Recomnendations for correcting and improving performance should be included. 



\section{CONTENTS}

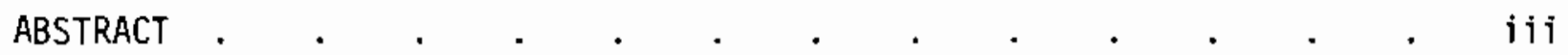

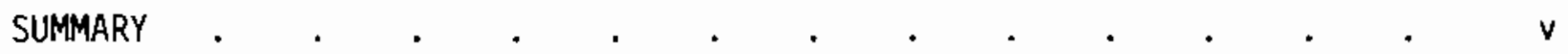

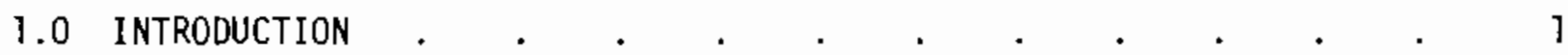

2.0 REQUIREMENTS FOR MEASUREMENT CONTROL PROGRAM AUDITING . . $\quad 3$

2.1 SCOPE OF THE AUDITS . . . . . . . . . . . . . . . . 3

2.2 AUDITOR QUALIFICATIONS AND TRAINING $\quad . \quad$. $\quad . \quad . \quad . \quad 4$

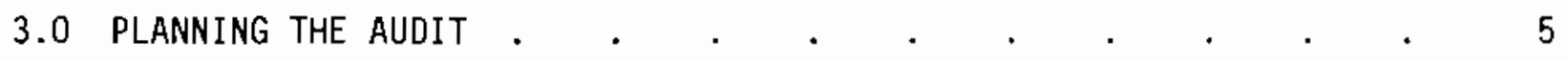

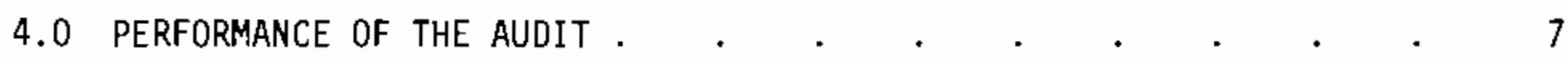

4.1 PROGRAM MANAGEMENT AND ORGANIZATION $\quad . \quad$. . . . . . 7

4.2 MANAGEMENT POLICIES AND PROCEDURES . . . . . . . . . 7

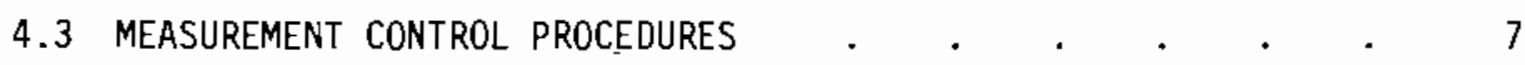

4.4 MEASUREMENT CONTROL DATA COLLECTION AND ANALYSIS . . . 8

4.5 RECORDS AND REPORTS . . . . . . . . . . . . . 9

4.6 PREVIOUS PROGRAM AUDITS . . . . . . . . . . . . 10

4.7 THE AUDIT REPORT $. \quad . \quad . \quad . \quad . \quad . \quad . \quad . \quad . \quad . \quad . \quad . \quad . \quad 10$

REFERENCES . . . . . . . . . . . . . . . . . . . 11

APPENDIX A - Example Checklist for Auditing Measurement Control
Programs . . . . . . . . . . . A-1 
$-$ 


\subsection{INTRODUCTION}

This report was prepared by Pacific Northwest Laboratory $(P N L)^{(a)}$ for the Safeguards Standards Branch, Office of Standards Development of the Nuclear Regulatory Commission (NRC) as part of a program for developing guidelines on measurement control for special nuclear material (SNM) control and accounting.

Licensees who are authorized to possess and own SNM in excess of certain quanti:iies $^{(b)}$ are required to implement and maintain formal programs for monitoring and controlling the quality of measurements made for SNM accounting. The requirements for such measurement control programs are specified in 10 CFR 70.57 and 70.58 . As part of these requirements, the licensee must perform an annual audit of the measurement control program to verify that the current practices conform to the regulations and to any license conditions imposed by NRC. The audit should also provide an assessment of the adequacy of the measurement control program. (c)

Measurement control for SNM accounting involves many highly technical functions. Special considerations are needed for developing audit plans, selecting audit personnel and performing the audits. This report presents general guidelines to assist in preparing for and performing these audits.

\footnotetext{
(a) PNL is operated by Battelle Memorial Institute.

(b)A quantity of material exceeding one effective kilogram of SNM for use in activities other than those involved in 1) operation of a nuclear reactor licensed pursuant to 10 CFR 50 or 2) those involved in a waste disposal operation, or as sealed sources.

(c) The term audit is used in this report to identify the functions of both reviews and audits as these functions are defined in 10 CFR 70.57 (b)(2).
} 



\subsection{REQUIREMENTS FOR MEASUREMENT CONTROL PROGRAM AUDITING}

A measurement control program encompasses a wide range of integrated activities that are intended to monitor and control the quality of measurements used in accounting for SNM. ${ }^{(2)}$ Program audits are an important aspect of a measurement control program. They are designed to provide an independent assessment of the measurement control program by: 1) verifying that the various functions are accomplished in accordance with written program procedures and that these procedures comply with management directives, license conditions and NRC regulations; and 2) assessing the adequacy of current measurement and measurement control procedures.

\subsection{SCOPE OF THE AUDITS}

The audit generaliy includes a comprehensive examination of all aspects of the measurement control program. The following specific areas should be examined:

- organization

- management policies and procedures

- measurement quality control procedures

- measurement control data collection and anaiyses

- measurement control records and reports

- previous measurement control program audits.

Audits are normally conducted annually. After initial implementation of the measurement control program, or a major change has been made on the program, and after any audit indicates weaknesses or inadequacies, more frequent audits may be desirable. The various parts of the measurement control program may be audited at different times during each 12-month period.

The annual audit requirement also applies to measurements performed for the licensee by outside contractors. It is the responsibility of the licensee to verify that the contractor's measurement control practices comply with the relevant NRC regulations and the licensee's policies. 


\subsection{AUDITOR QUALIFICATIONS AND TRAINING}

It is important that measurement control program audits be performed by trained individuals. At a minimum the training should consist of college level studies in mathematics, chemistry, physics, engineering, and quality control. In addition, an auditor needs to understand measurement technology and measurement control principles. Audit team personnel should be sufficiently knowledgeable to permit evaluation of the appropriateness and the effectiveness of measurement control procedures. Experience in auditing or training in auditing practices by an experienced auditor is also important and at least one auditor on the team should be competent in basic statistics. If not, it is necessary to have a statistician available for consultation on statistical problems that may arise during the course of the audit.

The audit team may be selected from the facility staff or contracted from outside the licensee's organization. The people assigned to the team should not have responsibilities for the functions to be audited. Auditors are required to make judgments concerning conformity of practices with written procedures, and to evaluate the adequacy of the program and the procedures used for monitoring and controlling measurement quality: Independent judgment and objectivity are necessary. 


\subsection{PLANNING THE AUDIT}

Before performing an audit of the measurement control program, a general audit plan should be prepared. The plan defines the scope of the audit, identifies the activities to be audited, outlines the requirements, lists documents and records needed, and gives the schedule and manpower required. The preparation of the audit plan requires a thorough review of all pertinent NRC regulations, license conditions, the licensee's measurement control plan, instructions, procedures or other documents applicable to measurement control, and the previous audit report.

It is advisable to prepare detailed checklists to serve as guides for the auditors to help insure that all significant parts of the measurement control program are included in the audit. An example checklist is included as Appendix $A$ to this report. The example is not intended to serve as a universal checklist because each facility will have unique features. The checklists should be designed around the specific facility measurement control program.

The general audit plan and the accompanying checklist should be sufficiently flexible to allow the auditor the freedom to pursue inquiries into any part of the measurement control program that is necessary to make informed judgments on compliance and adequacy.

Before the audit is made, the audit team should meet with the facility management and the staff responsible for measurement quality. At this meeting the audit team can describe the purpose and scope of the audit. Arrangements can be made for obtaining records and reports and for scheduling interviews with facility personnel or plant tours needed to carry out the audit. Recent changes in the measurement control program, and particularly any corrective actions resulting from the recommendations of the previous audit, can be identified. Areas that management wishes emphasized in the audit can be discussed and incorporated in the audit plan. 
$\because$ 


\subsection{PERFORMANCE OF THE AUDIT}

The following paragraphs outline the principal areas that are to be examined in an audit of the measurement control program.

\subsection{PROGRAM MANAGEMENT AND DRGANIZATION}

The review of management functions and the facility organization can determine whether: 1) the duties and authorities for all measurement control activities are defined in writing, 2) the measurement control function is assigned to specific individuals who are responsible and accountabie for that function, and 3) these assignments are current and reflect actual practices. The auditor(s) can then verify that the measurement control program management is independent of responsibilities for production, analytical chemistry, or other functions that may result in conflicting goals, and that a single individual is responsible for overall administration of the measurement control function.

\subsection{MANAGEMENT POLICIES AND PROCEDURES}

The manual for measurement control is examined to determine whether it contains policies and procedures that are consistent with applicable NRC regulations and license conditions. This is normaliy done during preparation of the audit plan. Checklists developed during the planning are structured to assure that the manual is up-to-date and coincides with current practices at the facility.

\subsection{MEASUREMENT CONTROL PROCEDURES}

The procedures for the control of measurement quality, i.e., control of the accuracy and precision of bulk measurements, sampling and analyses, are reviewed and compared with actual practices to verify that:

- All measurement systems have undergone engineering analyses, evaluations and tests, and that these analyses, evaluations and tests show that the design and installations are adequate for the intended measurements. 
- Only approved sampling and measurement methods are being used; direct observations should be used whenever possible to verify that written procedures are being followed.

- Personnel who perform measurements or who sample bulk materials are trained and qualified for those functions, and that their qualifications are documented.

- Calibrations of measurement systems are performed according to written procedures at the prescribed frequencies, and that no instruments, scales, balances, other measurement devices or standards are used whose calibration period has expired. Calibration data should be available for review by the audit team in accordance with the records requirements of 10 CFR 70.57 (b)(12).

- Control charts or other statistical tests are used to continually monitor the quality of measurements for each type of measurement and that corrective action is taken when the control limits are exceeded.

- Calibration frequencies are adequate for control of measurement performance.

- Standards used for calibrations cover the applicable measurement ranges, are representative of the materials being measured, and are traceable to a national measurement system.

- Protective measures are used to insure integrity of standards.

- Special measurement requirements, such as temperature or humidity controls, are provided where needed.

- Procedures are prescribed by measurement control personnel and used for applying control limits, detecting and rejecting outlier measurement results, and detection of calculating and recording mistakes. (3)

\subsection{MEASUREMENT CONTROL DATA COLLECTION AND ANALYSIS}

The procedures for acquisition of measurement control data and the statistical methods for estimating measurement errors should be examined and compared with actual practices to determine whether: 
- Random error variances of measurement processes are determined by a system of control measurements.

- The control system includes the replicate analysis of process samples, the replication of weight or volume measurements of bulk quantities of material, and the replicate analysis of replicate process samples according to a predetermined schedule.

- The control system can provide information necessary to identify and quantify individual sources of measurement error when required for diagnosis of measurement control problems.

- Measurement results are corrected for bias.

- Standards used for determining measurement bias are representative of the process materials being measured.

- The variances of calibrations and bias corrections are determined.

- Data used for error estimation are generated during the material balance period to which they are applied, or where data are pooled the sets of data are tested for equality.

- Correct statistical procedures are used to test measurement data and to estimate measurement error variances. $(4,5)$

Where there are indications that measurement quality has failed to meet accepted control limits, e.g., where data exceed applicable control limits, the auditor must evaluate the adequacy of remedial steps taken. Such steps should include determination of the principal sources of measurement error that contributed to the out-of-control condition.

\subsection{RECORDS AND REPORTS}

The measurement control program records and reports should be examined to determine if record keeping policies are being adhered to. The examination should usually include reviews of logbooks, laboratory notebooks, records of calibrations and standards, and records of method approvals and personnel qualifications. The completeness, accuracy, retrievability and traceability of the records should be evaluated. 
Every record or report need not be examined but, by using generally accepted auditing principles, ${ }^{(6)}$ representative samples of each type of record and report must be checked. The selection of samples of the records to be audited should be random. The size of the sample can be determined from a statistical sampling. (7) A typical set of parameters for an acceptance sampling plan based on a hypergeometric probability distribution is as follows:

- acceptance qualjty level $(\mathrm{AQL})=0.5 \%$

- reject quality level (RQL) = $5 \%$

- probability of committing Type I errors $=5 \%$

- probability of committing Type II errors $=5 \%$.

\subsection{PREVIOUS PROGRAM AUDITS}

It is important that the audit include a review of previous audits to determine if they have been performed in accordance with stated program policies and if previously identified defects have been corrected.

\subsection{THE AUDIT REPORT}

At the conclusion of an audit, the audit team should: 1) meet with facility management, including the SNM control and accounting management, to review the significant findings; and 2) prepare and submit a report containing the findings to facility management promptly after completion of the audit. The report should identify each aspect of the measurement control program that is judged to be unsatisfactory or conditionally acceptable. Conditionally acceptable items are practices that are judged to be in compliance with the relevant regulations and measurement control program policies, but are only marginally effective and require improvement.

Audit working papers should be examined and approved by the head of the audit team, and be filed along with copies of the audit report for future reference. 


\section{REFERENCES}

1. Code of Federal Regulations. "Title 10, Energy," Part 70, Superintendent of Documents, U.S. Government Printing Office, Washington, DC 2D402, January 1978.

2. A Measurement Control Program for Nuclear Material Accounting. Proceedings of the 15th Annual Meeting, Institute of Nuclear Materials Management, June 19-21, 1974, Atlanta, GA, Nuclear Mater. Manage. 3(3) 228-297, 1974.

3. Recommended Practices for Dealing with Outlying Observations. Regulatory Guide 5.36, U.S. Nuclear Regulatory Commission, Washington, DC 20555 , 1974 .

4. J. L. Jaech, Statistical Methods in Nuclear Material Control. TID-26298, Superintendent of Documents, U.S. Government Printing Office, Washington, DC 20402, 1973.

5. M. G. Natrella, "Experimental Statistics," NBS Handbook 91. National Bureau of Standards, Washington, DC 1963.

6. Herbert Arkin, Handbook of Sampling for Auditing and Accounting, Vol. 1, Methods. McGraw-Hi11 Book Co., Inc., New York, NY, 1963.

7. J. L. Jaech, op. cit. Chapter 9, Section 9.1. 


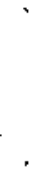




\section{APPENDIX A}

EXAMPLE CHECKLIST FOR AUDITING MEASUREMENT CONTROL PROGRAMS

A. MEASUREMENT CONTROL PROGRAM, GENERAL

Organization

Review the facility organization guide and the current organization charts and interview several personnel responsible for measurement control functions.

1. Is the responsibility for planning, developing, coordinating, and administering the measurement control program assigned to a single individual?

2. Does that individual have sufficient authority to maintain an effective measurement control program and sufficient independence from production and operating functions to make decisions about SNM measurement control objectively?

3. Are the duties and responsibilities of measurement control program personnel defined in written job descriptions?

4. Are these duties and responsibilities assigned to specific individuals?

5. Do the job descriptions and assignments coincide with actual current practices?

6. Do the individuals responsible for measurement control functions have any job responsibilities that may result in conflict of interest?

(a) Refer to auditor's attached comments by number. An explanation should be contained in the notes for each negative notation. 
7. Do the measurement control program personnel have capabilities in the areas of measurement technology, statistics and material accounting either within the group or through the use of other personnel within the facility?

\section{Program Policies and Procedures}

Review the Measurement Control Program Manual and compare with 1 icense conditions and appropriate federal regulations (i.e., 10 CFR Part 70 , Sections $70.51,70.57$, and 70.58$)$.

1. Are the measurement control program policies and functions understandable and unambiguous?

2. Does the manual describe the requirements and general procedures for:

- measurement quality control

- determining and monitoring random and systematic errors

- testing, evaluation, and approval of sampling and measurement procedures and control of changes to these procedures

- selection and approval of reference standards and calibration procedures

- training and qualification of measurement personnel

- maintenance of a records and reports system for measurement control data

- review of designs, installations, and tests of measurement facilities and equipment

- program reviews and audits? 


\section{B. MEASUREMENT QUALITY CONTROL}

Measurement Methods

Review the measurement procedures for each measurement and sampling point. Observe the practices in actual use.

1. Are detailed written procedures available at the work site for each measurement procedure (bulk measurement, sampling, analysis) for each type of material?

2. Do each of the measurement procedures have appropriate documented approvals as required by the approval procedures?

3. Are data available to show that the approval is based on technically sound testing?

4. Are measurement personnel qualified in accordance with a formal qualification program?

5. Are measurements carried out precisely as described in the procedures (10ok for special requirements such as environmental control, e.g., humidity or temperature requirements)?

- Where chemicals are used, are their purities specified and controlled?

6. Can the individuals who carry out the procedures be identified by records such as operating or laboratory logbooks or other documents?

7. Are the individuals performing measurements qualified?

8. Are written, approved procedures being used for calibrations and bias tests?

9. Are calibrations and bias tests carried out at a specified frequency?

10. Do the calibrations cover the entire range over which the measurements are made? 
11. Are calibration expiration dates for all calibrated equipment posted on or near the equipment?

12. Have any of the calibrations expired?

13. Are the reference standards used for calibration of equipment and measurement methods traceable to the National Measurement System?

14. Do any of the reference standards appear to have undergone damage or deterioration?

15. Have any of the reference standards that require periodic recertification or recalibration expired? (Expiration dates of all standards should be posted and documented.)

16. Are calibration data documented?

17. For chemical assays and NDA, are the working standards used for bias tests similar to our representative of the material being assayed?

Measurement Reliability

1. Are provisions made for determining the error variances associated with each measurement sys tem?

2. Are both variance components and biases determined?

3. Are all sources of error (e.g., bulk measurement, sampling, and anaiys is) accounted for in determining the overall measurement error variance?

4. Random error variances should be determined through a program of replicate measurements and replicate samples.

- Is this done for each measurement and sampling point?

- Do the data from replicate measurements and samples reflect current conditions (i.e., are the replicates performed during the material balance period to which they are applied)? 
- Do the replicate data include possible error sources due to different operators, time periods, and instruments?

5. Estimates of bias and the variance of the bias estimate should be made from measurements of standards, experimental tests (such as mixing and sampling tests) or comparative analyses.

- Are al1 known sources of error included in the variance of the bias estimates?

- Are working standards used for bias determinations traceable to a national measurement system?

- Do they closely simulate the process material?

- If standards are used which do not closely simulate the process material, have appropriate steps been taken to obtain valid estimates of the measurement error?

- Are measurement results corrected for bias?

- Are sampling biases determined from mixing and sampling system tests designed for the specific sampling system being evaluated?

- Where comparative analysis data are used for estimating the bias, is the referee method acceptable, i.e., are the precision and accuracy of the referee method known for the conditions used?

- Are acceptable statistical procedures used for estimating bias and variance components?

C. RECORDS AND REPORTS

Review the written procedures describing the records and reports system and compare with actual practices. 
1. Is the record and report system designed to assure proper retention of measurement control program information including records of calibrations, descriptions of standards, measurement control data, personnel qualifications, evaluations and approvals of measurement methods, audit and evaluation reports, and periodic reports on the status of the measurement control program?

2. Are the records and reports retained for specified periods?

3. Is the records and reports systenl designed to permit easy retrieval of information, and properly cross referenced to expedite the tracing of measurement control data to the original measurements or calibrations?

4. Are the designs of forms used for routine records and reports controlled?

- Is there a formal procedure for approval of changes?

5. Do actual record keeping practices conform to written procedures?

6. Are records and reports properly completed, including all of the required information, and signed or initialed where required?

7. Are laboratory notebooks and operating logbooks containing measurement control data properly maintained?

- Are the entries legible, understandable, signed, and dated?

8. Are the calculations of measurement results rechecked by a qualified second party?

9. How frequently?

\section{PREVIOUS AUDITS}

Examine reports of previous audits and management reviews.

1. Were audits and reviews performed at required frequencies? 
2. Do they fulfill the requirements as to scope and content as required by stated policies of the measurement control program?

3. Where program defects were identified, were necessary corrective actions taken in a timely fashion? 
. 


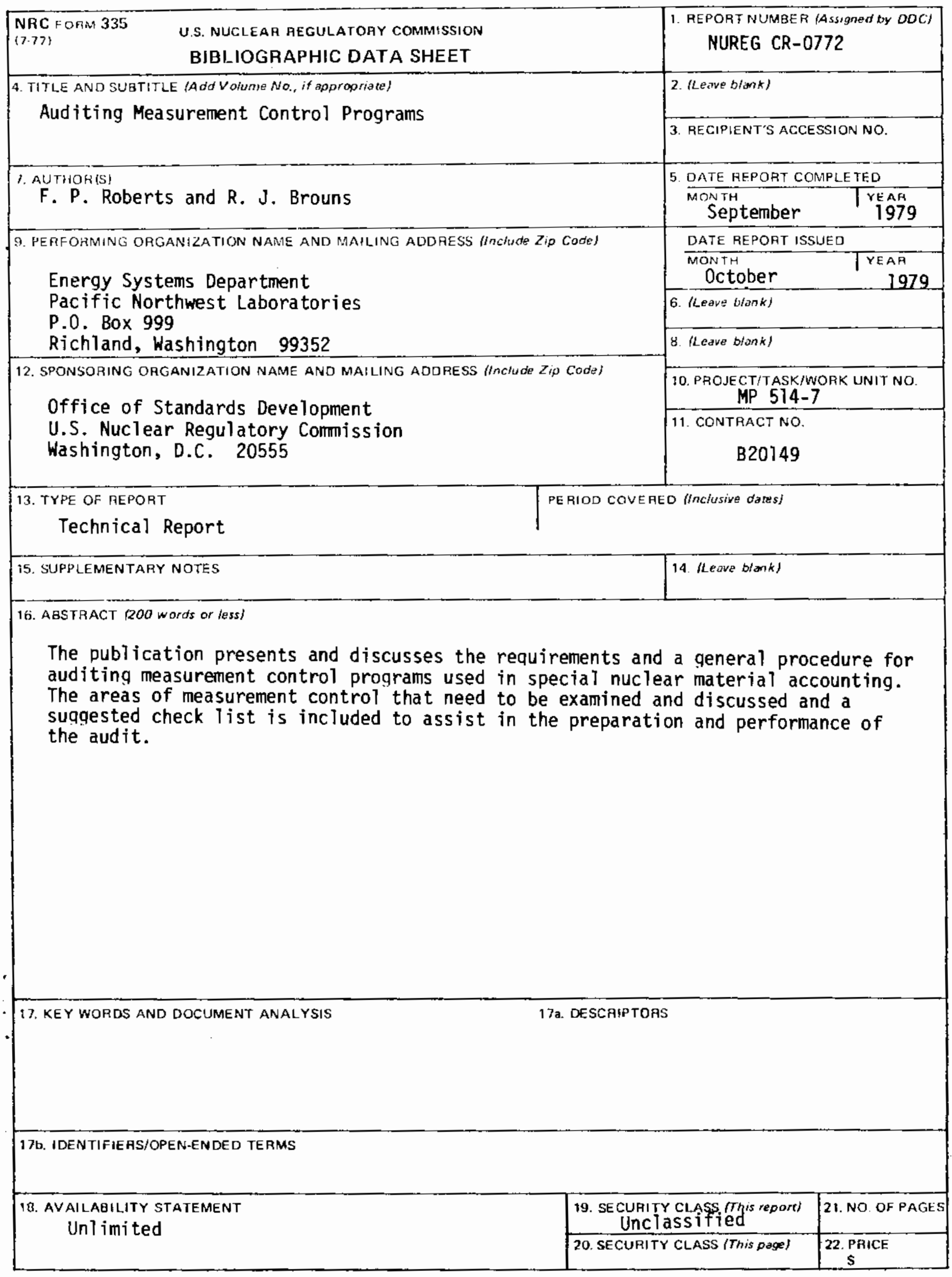


. 